\title{
Adverse childhood experiences and their relationship to gender and depression among young adults in Iraq: a cross- sectional study
}

\author{
Ameel F. Al Shawi ${ }^{1 *}\left(\mathbb{D}\right.$, Yassen T. Sarhan $^{2}$ and Mahasin A. Altaha ${ }^{2}$
}

\begin{abstract}
Background: Adverse childhood experiences (ACEs) are considered as universal public health problem that associate with mental disorders and risky behaviors during adulthood. The aims of the paper are to estimate the prevalence of Adverse childhood experiences (ACEs) among young adults in Iraq as well as to estimate the association between ACEs and depression.

Methods: A convenience sample of young adults of 18-20 years was chosen from centre and west of Iraq, mainly from universities. The adverse childhood experiences were measured by Adverse Childhood Experiences Questionnaire. A depression scale was derived from the Depression, Anxiety and Stress Scales (DASS). Statistical tests: chi square was used to measure the association between adverse childhood experiences and other variables like gender and depression. Odds ratios were computed to estimate the risk for depression. A $P$ value of less than 0.05 was considered statistically significant.

Results: The total number of participants was $401,38.9 \%$ of the subjects were men, while $61.1 \%$ were women. The mean age of the participants was $18.88 \pm 0.745$. The results revealed that the most common forms of ACEs among the subjects were physical neglect (19.8\%) and emotional neglect (19.2\%) followed by physical abuse (17.21\%) while sexual abuse was $7.52 \%$.

There was statistically significant association between most forms of adverse childhood experiences especially emotional abuse, emotional neglect, physical abuse and physical neglect with depression.

Conclusion: ACEs are not uncommon among young adults in Iraq and are associated with depression in adulthood. National programmes to support mental health rehabilitation might be necessary to reduce the effect of ACEs among Iraqi people, especially for adolescents and young adults.
\end{abstract}

Keywords: Adverse childhood experiences, Gender, Depression, Young adults, Iraq

\section{Background}

Adverse Childhood Experiences (ACEs) can be defined as 'all types of abuse, neglect, and other potentially traumatic experiences that occur to people under the age of 18 ' [1].

The literature has documented that ACEs are a global and universal issue that can have complicated and serious effects on physical, mental and social health during

\footnotetext{
*Correspondence: ameelalshawi@gmail.com; ameel_med@uofallujah.edu.iq ${ }^{1}$ Department of Community \& Family Medicine, College of Medicine, University of Fallujah, Fallujah, Iraq

Full list of author information is available at the end of the article
}

adulthood, also can lead to risky behaviours like alcohol consumption, drug abuse and even suicide attempts [2-5].

The association between exposure to traumatic events during childhood and the development of depression during adulthood has been addressed by several studies, which have demonstrated that the exposure of children to different kinds of violence leads to emotional, neurological deficits and maldevelopment that may occur not only during childhood but also later in life [6-9].

The prevalence of ACEs varies across the world, and while many studies reported a high prevalence of ACEs in

(c) The Author(s). 2019 Open Access This article is distributed under the terms of the Creative Commons Attribution 4.0 International License (http://creativecommons.org/licenses/by/4.0/), which permits unrestricted use, distribution, and reproduction in any medium, provided you give appropriate credit to the original author(s) and the source, provide a link to the Creative Commons license, and indicate if changes were made. The Creative Commons Public Domain Dedication waiver (http://creativecommons.org/publicdomain/zero/1.0/) applies to the data made available in this article, unless otherwise stated. 
regions with low per capita incomes, there are few longitudinal studies that address the effect of ACEs $[9,10]$.

In Iraq, studies that reported the prevalence of ACEs and their effects on adults, especially young adults, are scarce. This is despite the fact that Iraqi population have been exposed to different types of violence during recent decades, especially after 2003, that have had a negative impact on the mental health and behaviours of individuals and families [11, 12]. Only one previous study was carried out in Baghdad city in 2015 to estimate ACEs among Iraqis [11].

The current study draws on the Iraqi sample from the 'International study of pro/antisocial behavior in young adults (SOCIALDEVIANCE1820)' which is an ongoing cross-continental longitudinal study that includes data and researchers from multiple countries. Its main objective is to measure the universality of ACEs as risk factors for psychosocial problems [13].

The aims of this paper are to estimate the prevalence of ACEs among young adults in Iraq and to estimate the association between ACEs and depression.

\section{Methods}

\section{Study design}

A cross-sectional study was conducted during the period from October 2018 to April 2019.

\section{Study subjects}

A convenience (non - probability) sample of young adults of $18-20$ years was chosen from the centre and west of Iraq, mainly from universities (Baghdad, $\mathrm{Al}$ Mustansyria, Al Naharain, Anbar and Fallujah). These universities had students from different governorates in Iraq.

The study includes young adults living in the local community between the ages of 18 and 20 who could provide informed consent. Subjects having less than 4 years of schooling were excluded.

\section{Questionnaire}

The questionnaire consisted of questions for sociodemographic characteristics including age, gender, occupation (work, study, work and study, and do not work or study) and financial issues (Are you financially independent? Yes, No).

ACEs were measured by the ACE questionnaire, which consists of 36 questions and was designed to measure the occurrence of a set of experiences during childhood and adolescence [14]. Such experiences include multiple types of abuse and neglect (physical, sexual and emotional) or household dysfunction (mental illness of a household member, substance abuse by a family member, parental divorce or incarcerated family members) [15]. These questions included, for example 'While you were growing up, during your first 18 years of life: was anyone in your household depressed or mentally ill?' and 'During the first 18 years of your life how often did a parent, guardian or household member punch, kick or beat you?' The Cronbach's alpha for the ACE questionnaire in the current study was 0.77 .

A depression scale was derived from the Depression, Anxiety and Stress Scales (DASS), which is a widely used screening tool to assess symptoms of depression, anxiety, and stress in community settings. This had a good internal consistency, with a Cronbach's alpha of 0.88 [16].

The depression subscale consists of seven questions that measure hopelessness, low self-esteem and low positive affect $[16,17]$. Each item of the depression subscale comprises a statement such as in the past week: 'I couldn't seem to experience any positive feelings at all', 'I found it difficult to work up the initiative to do things', 'I felt that I had nothing to look forward to', 'I felt downhearted and blue', 'I was unable to become enthusiastic about anything', 'I felt I wasn't worth much as a person' and 'I felt that life was meaningless'. Four short-response options reflect the degree of agreement with the statement, scored from 0 (Did not apply to me at all) to 3 (Applied to me very much, or most of the time). A total score of 9 and below is considered normal, while a score of 10 and above is considered depressed [16, 18]. The Cronbach's alpha for the depression subscale in this study was 0.80 .

The final version of the questionnaire was translated from English to Arabic by an expert from the Community Medicine Department at the University of Fallujah. The approval for the study was made by the Scientific Committee of the Medical College, University of Fallujah.

\section{Ethical issues}

The self- administered questionnaire form was anonymous. Verbal consent was taken from the participants after explaining the aims of the study, assuring them that all information would be kept strictly confidential.

\section{Data analysis}

Data entry followed by descriptive and analytic statistics were carried out using Excel and the Statistical Package for Social Science (SPSS- version 21).

Frequencies and proportions were calculated during the descriptive analysis. Chi-square was used to measure the association between ACEs and other variables like gender and depression. Odds ratios were computed to estimate the risk for depression. A $P$-value of less than 0.05 was considered statistically significant. 


\section{Results}

The total number of participants was $401,38.9 \%$ of the subjects were men, while $61.1 \%$ were women. The mean age of the participants was $18.8 \pm 0.7$ years. $6.2 \%$ of the sample was financially independent (Table 1).

Regarding the prevalence of ACEs among the participants, the results showed that the most common forms of ACE were physical neglect (19.8\%) and emotional neglect (19.2\%), then physical abuse (17.2\%). Exposure to domestic violence was reported by $16.5 \%$ of the subjects, mental illness in the household was reported by $8.2 \%$ of the participants, while the proportion of participants reporting sexual abuse was $7.5 \%$. The ACE score showed that $17.2 \%$ of the subjects experienced one ACE, $16.5 \%$ of the subjects experienced two ACEs, while $7.5 \%$ of the participants experienced four or more ACEs (Table 2).

Regarding gender and ACEs, the most prevalent form of ACEs among men was physical abuse (25\%) while the most prevalent form of ACEs among women was physical neglect (19.6\%). The rate of sexual abuse among male subjects was $12.3 \%$ and among female subjects was $4.5 \%$. Generally the prevalence of abuse forms (physical and emotional) was higher among men than women. More details are provided in Table 2.

The results revealed that there was statistically significant association between most forms of ACE, especially emotional abuse $(\mathrm{OR}=2.29$, C.I. $=1.01-$ $5.17)$, emotional neglect $(\mathrm{OR}=2.78$, C.I. $=1.69$ 4.64), physical abuse $(\mathrm{OR}=1.71$, C.I. $=1.00-2.90)$ and physical neglect $(\mathrm{OR}=2.13$, C.I. $=1.28-3.53)$ with depression. There was a statistically nonsignificant association between exposure to domestic violence and depression. On the other hand, there

Table 1 Sociodemographic characteristics of the subjects

\begin{tabular}{lll}
\hline & $\mathrm{n}$ & $\%$ \\
\hline Gender & & \\
Males & 156 & 38.9 \\
Females & 245 & 61.1 \\
Total & 401 & 100.0 \\
Occupation & & \\
Working & 3 & 0.7 \\
Studying & 381 & 95.0 \\
Working and Studying & 16 & 4.0 \\
Did not study or work & 1 & 0.2 \\
Total & 401 & 100.0 \\
Financially Independent & & \\
Yes & 25 & 6.2 \\
No & 375 & 93.5 \\
Total & $400^{*}$ & 99.8 \\
\hline * 401 due to missed questions & &
\end{tabular}

was a statistically significant association between a high ACE score and depression (Table 3).

Regarding the association between ACEs and depression by gender, for men the experiences of sexual or physical abuse as well as physical neglect had a statistically significant association with depression, while for women there was a significant association between emotional or physical neglects and mental illness in households with depression (Table 4).

\section{Discussion}

ACEs are considered a public health problem [15, 19]. The current study sought to estimate the prevalence of ACEs (abuse, neglect and household dysfunction) among a convenience sample of young adults in Iraq, and the relationship of ACEs to depression symptoms.

The prevalence of physical abuse and neglect was higher than that of adolescents in Brazil (6.9 and $4.6 \%$ respectively) [20], in Finland $(0.2$ and $0.1 \%$ respectively) [21], and also higher than what was reported among university students in Germany (3.9 and $4.6 \%$ respectively) [3]. The prevalence of physical neglect was higher than for university students in Turkey (5.7\%) [4]. The prevalence of domestic violence was higher than that reported in eastern European countries (14.6\%) [9] and in Brazil (10.3\%) [20]. The high prevalence of physical abuse, neglect and exposure to domestic violence in the current study could be due to Iraq and Iraqis being exposed to different kinds of violence and traumatic events for decades, especially after the 2003 US invasion of Iraq, which had serious consequences on the behaviours of individuals and families [12, 22].

The proportion of emotional neglect was similar to what was reported in Brazil (19.7\%) [20] and in Germany (19.1\%) [3]. The literature shows that psychological maltreatment was the main form of child abuse in many countries $[19,20]$.

The results revealed that sexual abuse was not uncommon, with rates of sexual abuse (7.5\%) higher than those reported in Lithuania (3.5\%), in Romania (5.8\%) [10] and in Brazil (1.4\%) [19]. However, it was lower than what was reported in Germany (12.3\%) [3] and at a similar rate to university students in Turkey (7.9\%) [4].

The study showed that the prevalence of sexual abuse was higher among men than women, which is inconsistent with other studies $[2,4,20]$. This might be due to culture and generally insecure condition of Iraq; as sexual abuse is a very sensitive issue and is stigmatised, it may be that there was underreporting of the prevalence of sexual abuse among women who may have been afraid to report such events, even though the questionnaire was anonymous and 
Table 2 Frequency of ACEs among the participants

\begin{tabular}{|c|c|c|c|c|c|c|c|}
\hline & \multirow{2}{*}{\multicolumn{2}{|c|}{ Total }} & \multicolumn{4}{|c|}{ Gender } & \multirow[b]{3}{*}{$P^{*}$} \\
\hline & & & \multicolumn{2}{|c|}{ Males } & \multicolumn{2}{|c|}{ Females } & \\
\hline & $\mathrm{N}$ & $\%$ & $n$ & $\%$ & $n$ & $\%$ & \\
\hline \multicolumn{8}{|c|}{ Emotional Abuse } \\
\hline no & 374 & 93.3 & 142 & 91.6 & 232 & 95.1 & \multirow[t]{2}{*}{0.163} \\
\hline yes & 25 & 6.27 & 13 & 8.4 & 12 & 4.9 & \\
\hline \multicolumn{8}{|c|}{ Physical Abuse } \\
\hline no & 332 & 82.79 & 117 & 75 & 215 & 87.8 & \multirow[t]{2}{*}{0.001} \\
\hline yes & 69 & 17.21 & 39 & 25 & 30 & 12.2 & \\
\hline \multicolumn{8}{|c|}{ Sexual Abuse } \\
\hline no & 369 & 92.48 & 136 & 87. & 233 & 95.5 & \multirow[t]{2}{*}{0.004} \\
\hline yes & 30 & 7.52 & 19 & 12.3 & 11 & 4.5 & \\
\hline \multicolumn{8}{|c|}{ Emotional Neglect } \\
\hline no & 320 & 79.8 & 125 & 81.7 & 195 & 80.8 & \multirow[t]{2}{*}{0.413} \\
\hline yes & 76 & 19.2 & 28 & 18.3 & 48 & 19.2 & \\
\hline \multicolumn{8}{|c|}{ Physical Neglect } \\
\hline no & 316 & 80.2 & 123 & 79.9 & 193 & 80.4 & \multirow[t]{2}{*}{0.894} \\
\hline yes & 78 & 19.8 & 31 & 20.1 & 47 & 19.6 & \\
\hline \multicolumn{8}{|c|}{ Exposure to domestic violence } \\
\hline no & 333 & 83.46 & 126 & 80.8 & 207 & 85.2 & \multirow[t]{2}{*}{0.247} \\
\hline yes & 66 & 16.54 & 30 & 19.2 & 36 & 14.8 & \\
\hline \multicolumn{8}{|c|}{ Substance Abuse household } \\
\hline no & 388 & 96.76 & 152 & 97.4 & 236 & 96.3 & \multirow[t]{2}{*}{0.541} \\
\hline yes & 13 & 3.24 & 4 & 2.6 & 9 & 3.7 & \\
\hline \multicolumn{8}{|c|}{ Mental illness in household } \\
\hline no & 368 & 91.8 & 138 & 88.5 & 230 & 93.9 & \multirow[t]{2}{*}{0.054} \\
\hline yes & 33 & 8.23 & 18 & 11.5 & 15 & 6.1 & \\
\hline \multicolumn{8}{|c|}{ ACEs score } \\
\hline 0 & 193 & 48.1 & 64 & 43 & 129 & 55.6 & \multirow[t]{5}{*}{0.125} \\
\hline 1 & 69 & 17.2 & 31 & 20.8 & 38 & 16.4 & \\
\hline 2 & 66 & 16.5 & 27 & 18.1 & 39 & 16.8 & \\
\hline 3 & 23 & 5.7 & 11 & 7.4 & 12 & 5.2 & \\
\hline $4+$ & 30 & 7.5 & 16 & 10.6 & 14 & 6 & \\
\hline
\end{tabular}

*P for chi square

confidential. Furthermore, sexual abuse might occur during early childhood and individuals may be unable to remember such events, leading to recall bias.

The association between exposure to different forms of ACEs (neglect and abuse) with depression, and the association between a high ACE score and depression, is consistent with what has been reported in other studies [21, 23]. Traumatic events during childhood have prolonged effects on the personality and emotions of individuals, with many studies showing that the abnormality of the hypothalamicpituitary-adrenal axis is a regular consequence of ACEs and might be the cause of psychopathological conditions in adults [24].
The results revealed no significant association between domestic violence and depression. The lack of association may be because male domination in relationships is an accepted norm, and therefore is not associated with depression. Or, given the continuous stressful conditions Iraqi families have experienced for a long time, it may be that other forms of violence exposure, such as to war, are more immediately important [22].

There was a difference between genders for the association between depression and exposure to certain forms of ACEs, as women were affected mainly by emotional neglect and mental illness in the household. Various studies have shown the association of women's higher 
Table 3 The association between ACEs and depression

\begin{tabular}{|c|c|c|c|c|c|}
\hline \multirow[t]{3}{*}{ ACEs } & \multicolumn{5}{|c|}{ Depression category } \\
\hline & \multirow{2}{*}{$\begin{array}{l}\text { Non-depressed } \\
\text { n (\%) }\end{array}$} & \multirow{2}{*}{$\begin{array}{l}\text { Depressed } \\
\mathrm{n}(\%)\end{array}$} & \multirow[t]{2}{*}{$P^{*}$} & \multirow[t]{2}{*}{$O R$} & \multirow[t]{2}{*}{$95 \% \mathrm{Cl}$} \\
\hline & & & & & \\
\hline \multicolumn{6}{|c|}{ Emotional Abuse } \\
\hline$n o^{* *}$ & $254(95.5)$ & $120(90.2)$ & \multirow[t]{2}{*}{0.041} & \multirow[t]{2}{*}{2.293} & \multirow[t]{2}{*}{$1.01-5.17$} \\
\hline yes & $12(4.5)$ & $13(9.8)$ & & & \\
\hline \multicolumn{6}{|c|}{ Emotional Neglect } \\
\hline no & $228(86.4)$ & $91(69.5)$ & \multirow[t]{2}{*}{0.001} & \multirow[t]{2}{*}{2.784} & \multirow[t]{2}{*}{$1.66-4.64$} \\
\hline yes & $36(13.6)$ & $40(30.5)$ & & & \\
\hline \multicolumn{6}{|c|}{ Physical Abuse } \\
\hline no & $229(85.4)$ & $103(77.4)$ & \multirow[t]{2}{*}{0.046} & \multirow[t]{2}{*}{1.71} & \multirow[t]{2}{*}{$1.00-2.90$} \\
\hline yes & $39(14.5)$ & $30(22.6)$ & & & \\
\hline \multicolumn{6}{|c|}{ Physical Neglect } \\
\hline no & $222(84.4)$ & $94(71.8)$ & \multirow[t]{2}{*}{0.003} & \multirow[t]{2}{*}{2.131} & \multirow[t]{2}{*}{$1.28-3.53$} \\
\hline yes & $41(15.6)$ & $37(28.2)$ & & & \\
\hline \multicolumn{6}{|c|}{ Sexual Abuse } \\
\hline no & $251(94.4)$ & $118(88.7)$ & \multirow[t]{2}{*}{0.044} & \multirow[t]{2}{*}{2.127} & \multirow[t]{2}{*}{$1.00-4.49$} \\
\hline yes & $15(5.6)$ & $15(11.3)$ & & & \\
\hline \multicolumn{6}{|c|}{ Exposure to domestic violence } \\
\hline no & $224(84.2)$ & $109(82)$ & \multirow[t]{2}{*}{0.568} & \multirow[t]{2}{*}{1.147} & $0.67-2.03$ \\
\hline yes & $42(15.8)$ & $24(18)$ & & & \\
\hline Substan & & & & & \\
\hline no & $262(97.8)$ & $126(94.7)$ & 0.107 & 2.426 & $0.79-7.36$ \\
\hline yes & $6(2.2)$ & $7(5.3)$ & & & \\
\hline Mental i & & & & & \\
\hline no & $253(94.4)$ & 115 (86.5) & 0.006 & 2.64 & $1.28-5.42$ \\
\hline yes & $15(5.6)$ & $18(13.5)$ & & & \\
\hline ACEs scC & & & & & \\
\hline 0 & $142(46.6)$ & $50(38.8)$ & $<0.001$ & & \\
\hline 1 & $48(19.1)$ & $21(16.3)$ & & & \\
\hline 2 & $36(14.3)$ & $30(23.3)$ & & & \\
\hline 3 & $8(3.2)$ & 15 (11.6) & & & \\
\hline $4+$ & $17(6.8)$ & $13(10.1)$ & & & \\
\hline
\end{tabular}

*P for chi square

** (no) is the reference category

reporting of emotional abuse during childhood and worse health outcomes [21, 25, 26].

\section{Limitations}

There were certain limitations to this study. First, it was difficult to provide a randomised sample of young adults (some young adults were students, others were working, while others were neither working nor studying). Furthermore, the current unstable situation of Iraq prevented visiting houses to conduct household to household surveys. Second, while we used forward translation procedures for the questionnaire, backward translation was not conducted. Third, adjusted regressions for the analyses were not done, so there might be underlying confounders.

\section{Conclusion}

ACEs are not uncommon among young adults in Iraq and are associated with depression in adulthood. National programmes to support mental health rehabilitation might be necessary to reduce the effect of ACEs among Iraqis, especially for adolescents and young adults. 
Table 4 Frequency of ACEs forms and gender with depression development

\begin{tabular}{l} 
Gender \\
\hline Males \\
Non depress (\%) \\
$100(93.5)$ \\
$7(6.5)$
\end{tabular}

\begin{tabular}{ll} 
Females & \\
\hline Non depressed & Depression \\
$\mathrm{n}(\%)$ & $\mathrm{n}(\%)$
\end{tabular}

Emotional Abuse

$\begin{array}{llllll}\text { no } & 100(93.5) & 42(87.5) & .216 & 154(96.9) & 78(91.8) \\ \text { yes } & 7(6.5) & 6(12.5) & & 5(3.1) & 7(8.2)\end{array}$

Physical Abuse

$\begin{array}{lllccc}\text { no } & 86(79.6) & 31(64.6) & .045^{*} & 143(89.4) & 72(84.7) \\ \text { yes } & 22(20.4) & 17(35.4) & & 17(10.6) & 13(15.3)\end{array}$

Sexual Abuse

\begin{tabular}{|c|c|c|c|c|c|c|}
\hline no & $99(92.5)$ & $37(77.1)$ & .007 & $152(95.6)$ & $81(95.3)$ & .913 \\
\hline yes & $8(7.5)$ & $11(22.9)$ & & $7(4.4)$ & $4(4.7)$ & \\
\hline \multicolumn{7}{|c|}{ motional Neglect } \\
\hline no & $89(84)$ & $36(77)$ & 0.277 & $139(88)$ & $55(65.5)$ & $<0.001^{*}$ \\
\hline yes & $17(16)$ & $11(23)$ & & $19(12)$ & $29(34.5)$ & \\
\hline \multicolumn{7}{|c|}{ hysical Neglect } \\
\hline no & $90(84.1)$ & $33(70)$ & $.048^{*}$ & $132(84.6)$ & $61(72.6)$ & $.026^{*}$ \\
\hline yes & $17(15.9)$ & $14(30)$ & & $24(15.4)$ & $23(27.4)$ & \\
\hline \multicolumn{7}{|c|}{ xposure to domestic violence } \\
\hline no & $91(84.3)$ & $35(72.9)$ & .097 & $133(84.2)$ & $74(87.1)$ & .546 \\
\hline yes & $17(15.7)$ & $13(27.1)$ & & $25(15.8)$ & $11(12.9)$ & \\
\hline \multicolumn{7}{|c|}{ lental illness in household } \\
\hline no & $98(90.7)$ & $40(83.3)$ & .181 & $155(96.9)$ & $75(88.2)$ & $.007^{*}$ \\
\hline yes & $10(9.3)$ & $8(16.7)$ & & $5(3.1)$ & $10(11.8)$ & \\
\hline
\end{tabular}

*P for chi square, and significant at level $<0.05$

\section{Abbreviations}

ACEs: Adverse Childhood Experiences; DASS: Depression, Anxiety and Stress Scales; SPSS: Statistical Package for Social Science; US: United states of America

\section{Acknowledgements}

The authors thank Dr. Miguel Basto-Pereira from William James Center for Research, ISPA - Instituto Universitário, Lisbon, Portugal) for his kind support and his assistant in preparation of the manuscript.

\section{Authors' contributions}

AFA: planned and carried out data collection and analysis, interpretation of the results, writing and reviewing the manuscript. YTS: planned and carried out data collection. MAA involved with interpretation of the results, and review of the manuscript. All authors reviewed and approved the manuscript.

\section{Funding}

No funding was received.

\section{Availability of data and materials}

The datasets used and/or analyzed during the current study available from the corresponding author on reasonable request.

\section{Ethics approval and consent to participate}

The ethical approval for the study was obtained from Scientific Committee in Medical College, University of Fallujah. The informed consent was verbal and was taken from all the respondents after explaining to them the purpose of the study, assuring them that all the information will be kept strictly confidential, the ethical commitee approved this procedure.

\section{Consent for publication}

Not Applicable.

\section{Competing interests}

The authors declare that they have no competing interests.

\section{Author details}

${ }^{1}$ Department of Community \& Family Medicine, College of Medicine, University of Fallujah, Fallujah, Iraq. ${ }^{2}$ Department of Community \& Family Medicine, College of Medicine, Anbar University, Ramadi, Iraq.

Received: 29 July 2019 Accepted: 18 November 2019 Published online: 16 December 2019

\section{References}

1. Centers for Disease Control and prevention (CDC). https://www.cdc.gov/ violenceprevention/childabuseandneglect/acestudy/aboutace.html. Access time: 29 Jun 2019

2. Hughes K, Bellis MA, Hardcastle KA, Sethi D, et al. The effect of multiple adverse childhood experiences on health: a systematic review and metaanalysis. Lancet Public Health. 2017;2:e356-66.

3. Wiehn J, Hornberg C, Fischer F. How adverse childhood experiences relate to single and multiple health risk behaviors in German public university students: a cross-sectional analysis. BMC Public Health. 2018;18:1005.

4. Dube SR, Miller JW, Brown DW, Giles WH, Felitti VJ, Dong M, Anda RF. Adverse childhood experiences and the association with ever using alcohol 
and initiating alcohol use during adolescence. J Adolesc Health. 2006;38: 444. e1-e10.

5. World Health organization (WHO). . Adverse childhood experiences survey among university students in Turkey. Study report-2013. http://www.euro. who.int/_data/assets/pdf_file/0010/267472/Adverse-childhoodexperiences-survey-among-university-students-in-Turkey-Eng.pdf. Access time: June 2019.

6. Chapman DP, Whitfield CL, Felitti VJ, Dube SR, Edwards VJ, Anda RF. Adverse childhood experiences and the risk of depressive disorders in adulthood. J Affect Disord. 2004;15(2):217-25.

7. Herzog Jl, Schmahl C. Adverse childhood experiences and the consequences on neurobiological, psychosocial, and somatic conditions across the lifespan. Front. Psychiatry. 2018;9:420. https://doi.org/10.3389/ fpsyt. 2018.0042

8. Pechtel P, Pizzagalli DA. Effects of early life stress on cognitive and affective function: an integrated review of human literature. Psychopharmacology. 2011;214(1):55-70. https://doi.org/10.1007/s00213-010-2009-2.

9. Bellis MA, Hughes K, Leckenby N, Jones L, et al. Adverse childhood experiences and associations with health-harming behaviors in young adults: surveys in eight eastern European countries. Bull World Health Organ. 2014;92:641-655B.

10. Sethi D, Bellis MA, Hughes K, Mitis F, Gilbert R, Galea G. European report on preventing child maltreatment. Copenhagen: World Health Organization Regional Office for Europe; 2013. https://apps.who.int/iris/bitstream/ handle/10665/108627/e96928.pdf;jsessionid=799233B338E3B22FBE8F57962 BC5184D?sequence $=1$

11. AlShawi AF, Lafta RK. Effect of adverse childhood experiences on physical health in adulthood: results of a study conducted in Baghdad city. J Fam Community Med. 2015;22:78-84.

12. Lafta R, Al-Nuaimi. War or health: a four-decade armed conflict in Iraq, Medicine, Conflict and Survival; 2019. https://doi.org/10.1080/13623699.2019. 1670431.

13. Basto-Pereira, M., Queiroz-Garcia, I., Maciel, L., et al. . international study of pro/antisocial behavior in young adults (in press). sagepub.com. 2019 journals-permissions httpDs:O//dlo: i1.o0r.g1/107.171/1770/ 6190639379171919885500741.

14. Dube SR, Felitti VJ, Dong M, et al. Childhood abuse, neglect and household dysfunction and the risk of illicit drug use: the adverse childhood experiences study. Pediatrics. 2003;110:564-72.

15. Felitti VJ, Anda RF, Nordenberg D, Williamson DF, et al. Relationship of childhood abuse and household dysfunction to many of the leading causes of death in adults the adverse childhood experiences (ACE) study. Am J Prev Med. 1998;14(4):245-58.

16. Tran TD, Tran T, Fisher J. Validation of the depression anxiety stress scales (DASS) 21 as a screening instrument for depression and anxiety in a rural communitybased cohort of northern Vietnamese women. BMC Psychiatry. 2013;13:24. Published online 2013 Jan 12. https://doi.org/10.1186/1471-244X-13-24.

17. Pezirkianidis C, Karakasidou E, Lakioti A, Stalikas A, Galanakis M. Psychometric properties of the depression, anxiety, stress scales-21 (DASS21) in a Greek sample. Psychology. 2018;9:2933-50.

18. Lovibond SH, Lovibond PF. Manual for the Depression Anxiety Stress Scales. 2. Sydney: Psychology Foundation of Australia; 1995. [Google Scholar] [Ref list].

19. Mwakanyamale A, Yizhen Y. Psychological maltreatment and its relationship with self-esteem and psychological stress among adolescents in Tanzania: a community based, cross-sectional study. BMC Psychiatry. 2019;19:176. https://doi.org/10.1186/s12888-019-2139-y.

20. Soares AL, Howe DL, Matijasevich A, et al. Adverse childhood experiences: prevalence and related factors in adolescents of a Brazilian birth cohort. Child Abuse Negl. 2016;51:21-30.

21. Rehan W, Antfolk J, Johansson A, Jern P, et al. Experiences of severe childhood maltreatment, depression, anxiety and alcohol abuse among adults in Finland. PLoS One. 2017;12(5):e0177252 https://doi.org/10.1371/ journal. pone.0177252.

22. Al-shawi AF, Al-Hemiary AJ, Al-Diwan JK, Tahir DH. Post-traumatic stress disorder among university students in Baghdad: a preliminary report. Iraqi J Comm Med. 2011;24:287-90.

23. Almuneef M, Hollinshead D, Saleheen H, AlMadani S, Derkash B, et al. Adverse childhood experiences and association with health, mental health, and risky behavior in the kingdom of Saudi Arabia. Child Abuse Negl. 2016;60:10-7.
24. Heim C, Newport DJ, Heit S, Graham YP, et al. Pituitary-adrenal and autonomic responses to stress in women after sexual and physical abuse in childhood. JAMA. 2000;284(5):592-7.

25. Ahmed AS. Post-traumatic stress disorders, resilience and vulnerability. Adv Psychiatr Treat. 2007;13(5):369-75 Google Scholar.

26. Collishaw S, Pickles A, Messer J, Rutter M, Shearer C, Maughan B. Resilience to adult psychopathology following childhood maltreatment: evidence from a community sample. Child Abuse Negl. 2007;31:211-29.

\section{Publisher's Note}

Springer Nature remains neutral with regard to jurisdictional claims in published maps and institutional affiliations.
Ready to submit your research? Choose BMC and benefit from:

- fast, convenient online submission

- thorough peer review by experienced researchers in your field

- rapid publication on acceptance

- support for research data, including large and complex data types

- gold Open Access which fosters wider collaboration and increased citations

- maximum visibility for your research: over $100 \mathrm{M}$ website views per year

At BMC, research is always in progress.

Learn more biomedcentral.com/submissions 